\title{
Anti-inflammatory and anxiolytic activities of Euphorbia hirta extract in neonatal asthmatic rats
}

\author{
Mingyue Xia, Ling Liu*, Ruiqin Qiu, Mingli Li, Wei Huang, Gaowei Ren and Jinghui Zhang
}

\begin{abstract}
The current study evaluated the anti-inflammatory and anxiolytic activities of Euphorbia hirta extract in neonatal asthmatic rats. Rats were assigned to the following groups: group I, sham (normal rats); group II, control (asthmatic rats); group III, E. hirta extract $(100 \mu \mathrm{g} / 100 \mu \mathrm{l})$ and group IV, E. hirta extract $(200 \mu \mathrm{g} / 100 \mu \mathrm{l})$. We performed a phytoscreening analysis of $E$. hirta extract. Inflammatory cell counts in the bronchoalveolar lavage fluid, levels of anti-inflammatory and antioxidant markers, apoptosis, and a histopathological analysis were carried out. An open field test determined anxiolytic activity, an elevated plus maze, a hole board test, and a cross test. The presence of 9,12,15-octadecatrien1-ol, pentadecylic acid, ethyl linoleate, 1,2,3-trihydroxy benzene, gamma-tocopherol, 5-hydroxymethyl-2-furancarboxaldehyde, myristic acid, 7,10-octadecadienoic acid methyl ester, phytol, ethyl palmitate, and squalene in E. hirta extract was noted. Following treatment with E. hirta extract, total leukocytes, eosinophils, tumor necrosis factor-a (TNF-a), interleukin (IL-6), and lipid peroxidation were reduced, whereas antioxidant levels were increased. The mRNA expression levels of TNF-a, inducible nitric oxide synthase, IL-6, cyclooxygenase-2, caspase-3, p53, nerve growth factor precursor, and Bax were reduced, whereas that of $\mathrm{Bcl}-2$ was increased. Apoptosis and caspase-3 protein expression were significantly reduced. Treatment of rats with $E$. hirta extract significantly reduced inflammation and eosinophil infiltration in the lungs. Taken together, these results led us to conclude that E. hirta extract has anti-inflammatory and anxiolytic effects on neonatal asthmatic rats with inflammation.
\end{abstract}

Keywords: Asthma, Euphorbia hirta, Caspase-3, Inflammation, Neonatal rats

\section{Introduction}

Plants and natural-derived medicines have attracted the attention of several researchers in China and India. Natural-derived medicines account for more than $20 \%$ of the drugs prescribed in developing countries (Rates 2001), and more than $70 \%$ of people use traditional naturalderived medicines for their health needs (Food and Agriculture Organization 2004). Nair et al. (2005) identified several plant parts that participate in numerous pharmacological activities. Euphorbia hirta is a familiar plant in the traditional medicine system and belongs to the family Euphorbiaceae (Kumar et al. 2010). Several researchers have reported that extracts of E. hirta perform various

*Correspondence: 10954001@qq.com

Department of Pediatrics, The First Hospital of Qinhuangdao, No. 258 of Seaport Cultural Road, Qinhuangdao 066000, China pharmacological functions, acting as an anxiolytic, sedative, anti-inflammatory, analgesic, and antipyretic agent. Indeed, it can be used to treat several conditions, such as hay asthma, worm infestations, bronchial infections, kidney stones, and bowel disease (Sharma et al. 2007; Salles et al. 1999).

Asthma is a well-known chronic disease of the lungs that affects the airways (Martinez 2007). Primary symptoms of asthma include bronchospasm, airflow obstruction, chest tightness, coughing, wheezing, and shortness of breath (Han et al. 2017). Asthma cannot be cured permanently; only the symptoms can be ameliorated by medications (Han et al. 2017). Avoidance of smoking, aspirin, and pets are the most efficient way to ameliorate asthmatic symptoms, and drugs are recommended based on symptom severity (Kelly et al. 1988). Bronchodilators are widely prescribed for the temporary relief from 
asthmatic symptoms (Shichinohe et al. 1996). Several studies have reported the antioxidant, anticancer, and anti-inflammatory activities of E. hirta extract (Sharma et al. 2014). Thus, the current study evaluated the antiinflammatory and anxiolytic effects of $E$. hirta extract on neonatal asthmatic rats.

\section{Materials and methods}

Rats

Male Sprague-Dawley neonatal rats (6-10 g) were obtained from the animal house of The First Hospital of Qinhuangdao, No. 258 of Seaport Cultural Road, Qinhuangdao 066000, China and divided into four groups. They were allowed standard access to food and water with a standard 12-h light/dark period. All animals were maintained on adaptive feeding before the experiments. All the animal experiments were approved by ethics committee of The First Hospital of Qinhuangdao, No. 258 of Seaport Cultural Road, Qinhuangdao 066000, China.

\section{Induction of asthma and animal groups}

Experimental asthma was induced in neonatal rats according to the previously described method (Feng et al. 2014). The following groups were used:

\section{Group I: $\quad$ Sham (normal rats); \\ Group II: Control (asthmatic rats); \\ Group III: Euphorbia hirta extract (asthmatic rats $+100 \mu \mathrm{g} / 100 \mu \mathrm{l})$; and \\ Group IV: Euphorbia hirta extract (asthmatic rats $+200 \mu \mathrm{g} / 100 \mu \mathrm{l})$}

The dose was given for 5 consecutive weeks via the oral route.

\section{Preparation of $E$. hirta leaf extract}

Euphorbia hirta leaves were collected from South China Agricultural University, China. Fresh leaves of E. hirta were harvested, washed in tap water, and air-dried for 7 days. Next, leaves were ground into a fine powder using an electric grinder and stored in an air-tight bottle. Euphorbia hirta powder (500 g) was extracted in $500 \mathrm{ml}$ of ethanol (95\%) using a Soxhlet apparatus for $60 \mathrm{~min}$. Finally, the extract was converted into solid form using a rotary evaporator (Sharma et al. 2014).

\section{Qualitative analysis of $E$. hirta extract}

Qualitative analysis of lemon peel extract was performed using high-performance liquid chromatography (HPLC). To determine the presence of a bioactive substance in $E$. hirta extract, HPLC was performed on a liquid chromatography system (Agilent 1200, Germany). Compounds were monitored on a C18 HPLC column. Ten microliters of sample were injected, and the column was operated at room temperature. The flow rate, which was adjusted to $0.5 \mathrm{ml} / \mathrm{min}$, consisted of a mobile phase containing acetonitrile (100\%) and acetic acid (0.5\%). Peaks were identified by comparing known standards and retention times (Jiang and Tu 2009).

\section{Collection of blood and preparation of lung tissue homogenate}

At the end of treatment, rats were anesthetized by intraperitoneal administration of ketamine $(100 \mathrm{mg} / \mathrm{kg})$ and xylazine $(10 \mathrm{mg} / \mathrm{kg})$. Rats were killed by decapitation, and blood was collected. Lung tissue was surgically removed, and tissues were cut and homogenized in Tris- $\mathrm{HCl}$ buffer ( $\mathrm{pH} 7.4,50 \mathrm{mM}$ ) at 10,000 rpm for $10 \mathrm{~min}$. Tissue homogenate was centrifuged, and the supernatant was collected for further experiments. All homogenate and supernatant preparations were performed at $4{ }^{\circ} \mathrm{C}$.

\section{Determination of inflammatory cell counts}

Inflammatory cell counts in the bronchoalveolar lavage fluid (BALF) were measured according to the previously described method (Feng et al. 2014).

\section{Determination of inflammatory and antioxidant markers}

Serum tumor necrosis factor- $\alpha$ (TNF- $\alpha$ ) and interleukin-6 (IL-6) levels were determined (Tavakkol Afshari et al. 2005). The nitric oxide (NO) level is expressed in $\mathrm{mM}$ (Shaheen et al. 2016). The mRNA expression levels of TNF- $\alpha$, IL-6, cyclooxygenase-2 (COX-2), and inducible nitric oxide synthase (iNOS) were measured according to the previously described method (Bernal et al. 2005). Primers specific to the above genes are shown in Table 1. Lipid peroxidation was determined according to malondialdehyde (MDA) content (Jordão et al. 2004). Reactive oxygen species (ROS) were determined using the dichlorofluorescein assay (Arutyunyan et al. 2016). The reduced glutathione (GSH) level was measured by determining the final product at $405 \mathrm{~nm}$ (ErdenInal et al. 2003). Superoxide dismutase (SOD), catalase, glutathione peroxidase (Gpx), and acetyl-cholinesterase (AChE) enzyme activities were measured spectrophotometrically (Jordão et al. 2004).

\section{Determination of apoptosis}

Terminal deoxynucleotidyl transferase dUTP nick end labeling (TUNEL) and staining was performed in lung sections as previously described (Sheikh-Hamad et al. 2004). Briefly, lung tissues were excised and perfused in normal saline, and then fixed in $10 \%$ neutral formalin (10\%) for $24 \mathrm{~h}$. Next, the lung sections were dehydrated with a graded series of alcohol and embedded in paraffin 
Table 1 List of RT-PCR primers used for the amplification of TNF-a, IL-6, COX-2, iNOS, caspase-3, proNGF, p53, bax and bcl-2

\begin{tabular}{|c|c|c|c|}
\hline S. no & Gene name & Forward & Reverse \\
\hline 1 & TNF-a & 5'-CCCAGACCCTCACACTCAGAT-3' & 5'-TTGTCCCTTGAAGAGAACCTG-3' \\
\hline 2 & $\mathrm{IL}-6$ & 5'-AAGTTTCTCTCCGCAAGATACTTCCAGCCA-3' & 5'-AGGCAAATTTCCTGGTTATATCCA GTTT-3' \\
\hline 3 & $\operatorname{cox}-2$ & $5^{\prime}$-CCATGTCAAAACCGTGGTGAATG-3' & 5'-ATGGGAGTTGGGCAGTCATCAG-3' \\
\hline 4 & iNOS & 5'-CTCCATGACTCTCAGCACAGAG-3' & 5'-GCACCGAAGATATCCTCATGAT-3' \\
\hline 5 & Caspase-3 & 5'-TTAATAAAGGTATCCATGGAGAACACT-3' & 5'-TTAGTGATAAAAATAGAGTTCTTTTGTGAG-3' \\
\hline 6 & proNGF & 5'-CTTCAGCATTCCCTTGACAC-3' & $5^{\prime}$-TGAGCACACACACGCAGGC-3' \\
\hline 7 & p53 & 5'-TAACAGTTCCTGCATGGGCGGC-3' & $5^{\prime}$-AGGACAGGCACAAACACGCACC-3' \\
\hline 8 & $\mathrm{BCl}-2$ & 5'-CACCCCTGG CATCTTCTCCTT-3' & 5'-AGCGTCTTCAGAGACAGCCAG-3' \\
\hline 9 & Bax & 5'-TGG AGCTGCAGAGGATGATTG-3' & 5'-GAAGTTGCCGTCAGAAAACATG-3' \\
\hline 10 & GAPDH & 5'-TCCCTCAAGATTGTCAGCAA-3' & 5'-AGATCCACAACGGATACATT-3' \\
\hline
\end{tabular}

film. Finally, the sections were cut (4-5 $\mu \mathrm{m}$ thick) with a rotary microtome and TUNEL staining was performed as previously described (Fayzullina and Martin 2014). The mRNA expression levels of caspase-3, p53, Bcl-2, $\mathrm{Bax}$, and nerve growth factor precursor (proNGF) were determined according to a previously described method (Bernal et al. 2005). Primers specific to the above genes are shown in Table 1. Protein expression of caspase-3 was analyzed by immunohistochemical staining (Rehg et al. 2012).

\section{Histopathological analysis}

Lung tissue was fixed in $10 \%$ neutral formalin and sliced into sections $(4-5 \mu \mathrm{m})$. Sections were then incubated with hematoxylin and eosin $(\mathrm{H} \& \mathrm{E})$ and analyzed under a microscope (Ding et al. 2011).

\section{Determination of anxiolytic activity}

Anxiolytic activity was determined using an open field test, an elevated plus maze, a hole board test, and a cross test according to a previous study (Amdadul et al. 2015).

\section{Statistical analysis}

Values are given as the mean \pm standard deviation. Oneway analysis of variance (ANOVA) was applied, and Tukey's post hoc test was used for multiple comparisons. A $\mathrm{P}$-value $<0.05$ was considered statistically significant.

\section{Results}

The anti-inflammatory and anxiolytic effects of $E$. hirta extract on neonatal asthmatic rats were investigated. The presence of 9,12,15-octadecatrien-1-ol (15.3\%), pentadecylic acid (11.6\%), ethyl linoleate (8.3\%), 1,2,3-trihydroxybenzene (2.2\%), gamma-tocopherol (0.92\%), 5-hydroxymethyl-2-furancarboxaldehyde (6.3\%), myristic acid (1.3\%), 7,10-octadecadienoic acid methyl ester (7.1\%), phytol (3.2\%), ethyl palmitate $(6.5 \%)$, and squalene $(1.2 \%)$ in E. hirta extract was noted.

The total leukocyte content was substantially increased in neonatal asthmatic rats compared to normal rats. Specifically, the total leukocyte content was increased by $459.5 \%$ in asthmatic rats, whereas treatment with $E$. hirta extracts significantly reduced the leukocyte content to $34 \%$ and $67 \%$ in groups III and IV, respectively (Fig. 1, $P<0.05$ ). The eosinophil content was substantially increased in asthmatic rats. Treatment with E. hirta extracts significantly reduced the eosinophil content to $28.9 \%$ and $64.4 \%$ in groups III and IV, respectively (Fig. $1, P<0.05$ ). The MDA content was determined as the end-product of lipid peroxidation and was drastically increased in control rats $(65.1 \mathrm{nmol} / \mathrm{g})$. Treatment with $E$. hirta extract significantly reduced the MDA content to $23.9 \%$ and $46.2 \%$ in groups III and IV, respectively (Table $2, P<0.05$ ). The GSH content was drastically reduced in neonatal asthmatic rats $(27.5 \mathrm{mg} / \mathrm{g})$, but it was significantly elevated, to $67.6 \%$ and $153 \%$, in groups III and IV, respectively (Table $2, P<0.05$ ). SOD, catalase, Gpx, and AChE enzyme activities were substantially reduced in asthmatic rats. However, treatment with E. hirta extract significantly increased enzyme activities (Table 2, $P<0.05)$. 


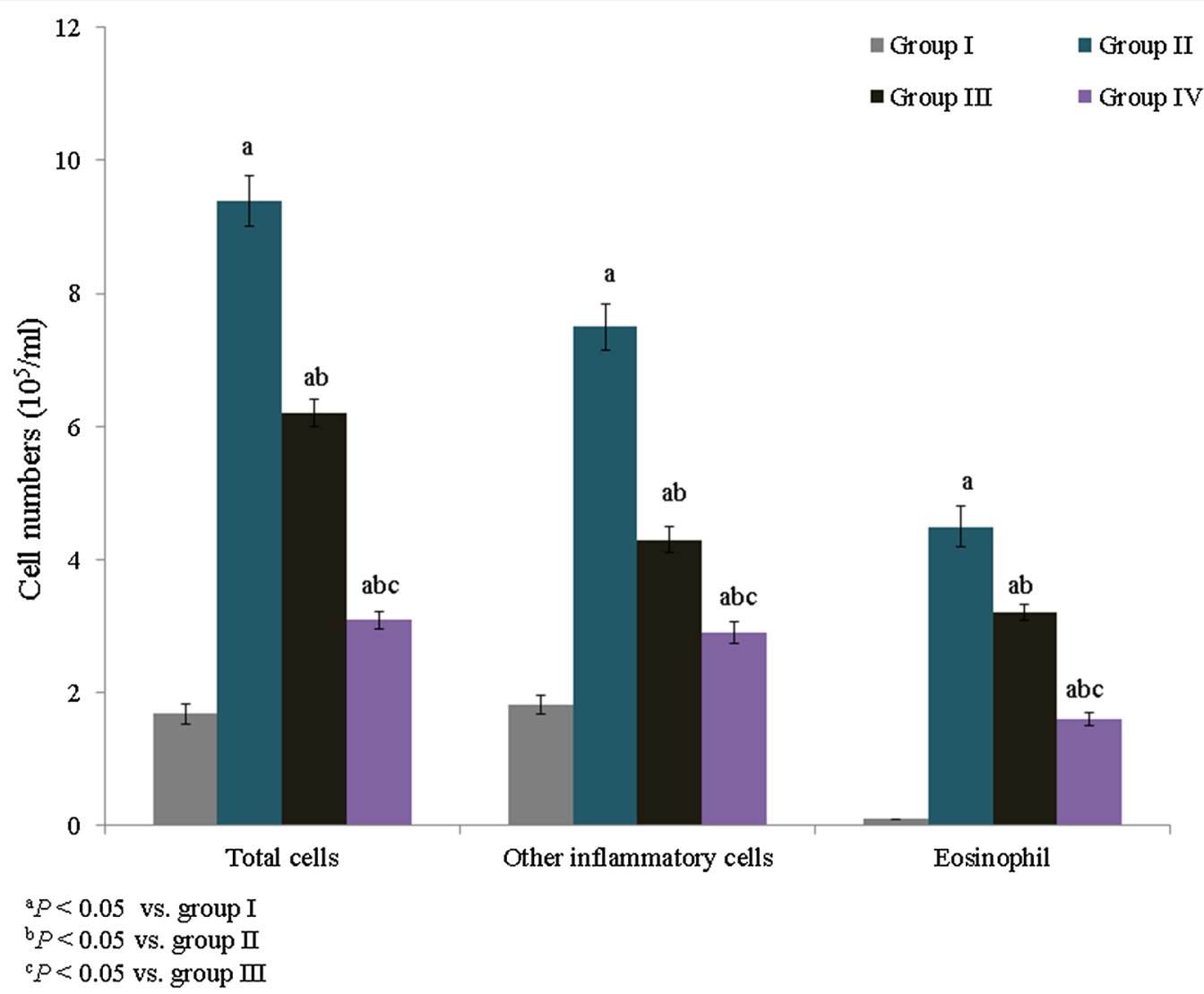

Fig. 1 Effect of E. hirta extract on inflammatory cell recruitment in the bronchoalveolar lavage fluid (BALF) of neonatal asthmatic rats. Experimental data are given as the mean \pm standard error of the mean (SEM)

Table 2 Effect of E. hirta extract on lipid peroxidation and antioxidant markers in neonatal asthmatic rats

\begin{tabular}{lcccc}
\hline Oxidative markers & Group I & Group II & Group III & Group IV \\
\hline MDA (nmol/g) & $25.5 \pm 1.6$ & $69.1 \pm 4.2^{\mathrm{a}}$ & $52.6 \pm 3.1^{\mathrm{ab}}$ & $37.3 \pm 2.4^{\mathrm{abc}}$ \\
GSH (mg/g) & $89.2 \pm 6.2$ & $27.5 \pm 1.8^{\mathrm{a}}$ & $46.1 \pm 3.2^{\mathrm{ab}}$ & $69.6 \pm 5.2^{\mathrm{bc}}$ \\
SOD (U/mg) & $7.3 \pm 0.54$ & $2.5 \pm 0.13^{\mathrm{a}}$ & $3.5 \pm 0.12^{\mathrm{ab}}$ & $4.9 \pm 0.15^{\mathrm{abc}}$ \\
Catalase (U/g) & $13.5 \pm 1.21$ & $4.2 \pm 0.24^{\mathrm{a}}$ & $6.9 \pm 0.23^{\mathrm{ab}}$ & $10.5 \pm 0.8^{\mathrm{bc}}$ \\
Gpx (mg/protein) & $0.96 \pm 0.008$ & $0.28 \pm 0.005^{\mathrm{a}}$ & $0.47 \pm 0.005^{\mathrm{ab}}$ & $0.77 \pm 0.006^{\mathrm{bc}}$ \\
AChE ( $\mu \mathrm{mol} / \mathrm{min} / \mathrm{mg}$ of protein) & $10.5 \pm 0.73$ & $3.1 \pm 0.15^{\mathrm{a}}$ & $6.3 \pm 0.22^{\mathrm{ab}}$ & $8.9 \pm 0.32^{\mathrm{bc}}$ \\
\hline
\end{tabular}

a $P<0.05$ vs. group I

b $P<0.05$ vs. group II

c $P<0.05$ vs. group III

The IL- 6 and TNF- $\alpha$ level were measured and are expressed as $\mathrm{pg} / \mathrm{mg}$ of protein. The IL- 6 and TNF- $\alpha$ levels were substantially increased (to more than 100\%) in asthmatic rats. However, treatment with E. hirta extracts significantly reduced the TNF- $\alpha$ level to $31.5 \%$ and $70 \%$ in groups III and IV, respectively (Fig. 2A, $P<0.05)$. The IL-6 level was also reduced following supplementation with $E$. hirta extract (Fig. 2A, $P<0.05$ ). 


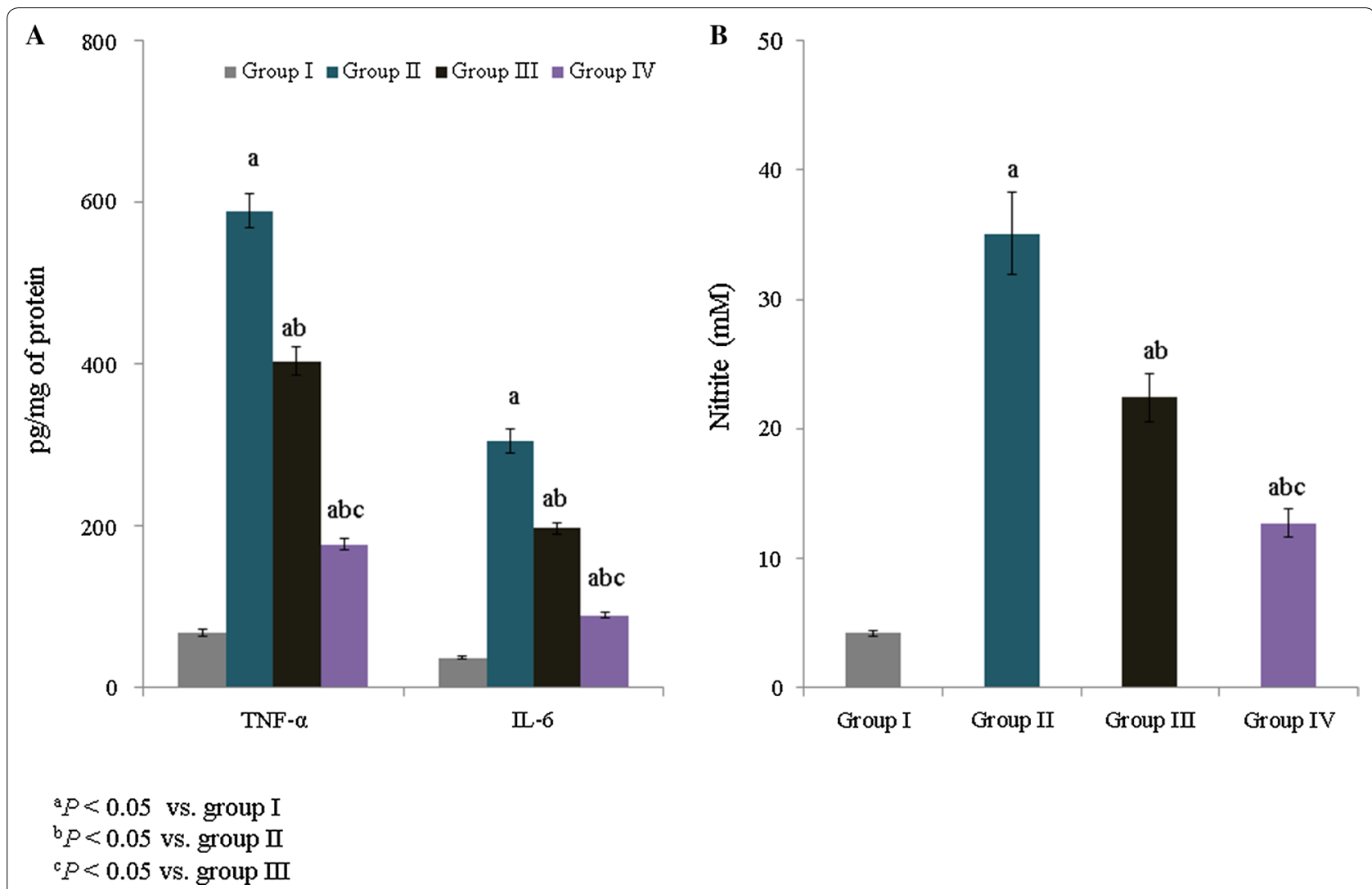

Fig. 2 Effect of E. hirta extract on tumor necrosis factor alpha (TNF-a), interleukin 6 (IL-6), and nitric oxide (NO) levels in neonatal asthmatic rats. A TNF-a and IL-6 levels are expressed as pg/mg of protein. B NO is expressed as mM. Experimental data are given as the mean \pm SEM

The NO concentration was substantially increased (to more than $100 \%$ ) in asthmatic rats. However, treatment with E. hirta extracts significantly reduced the NO level, to $36.2 \%$ and $63.8 \%$, in groups III and IV, respectively (Fig. 2B, $P<0.05$ ).

The mRNA expression levels of IL-6, TNF- $\alpha$, iNOS, and COX-2 were quantified and expressed as fold changes. TNF- $\alpha$, IL- 6 , iNOS, and COX-2 mRNA expression was increased by 1.2-, 1.1-, 0.8-, and 0.94-fold, respectively, in group II. However, treatment with $E$. hirta extracts significantly reduced TNF- $\alpha$, IL-6, iNOS, and COX-2 mRNA expression by more than 0.6-fold in group IV (Fig. 3, $P<0.05$ ). The percentage of apoptosis was substantially increased in asthmatic rats (53.6\%), whereas treatment with $E$. hirta extracts significantly reduced apoptosis to $30.8 \%$ and $69.4 \%$ in groups III and IV, respectively (Fig. $4, P<0.05$ ). The mRNA expression levels of inflammatory markers, caspase-3, proNGF, p53, Bax, and Bcl-2, were quantified and expressed as fold changes. The mRNA expression levels of caspase-3, 


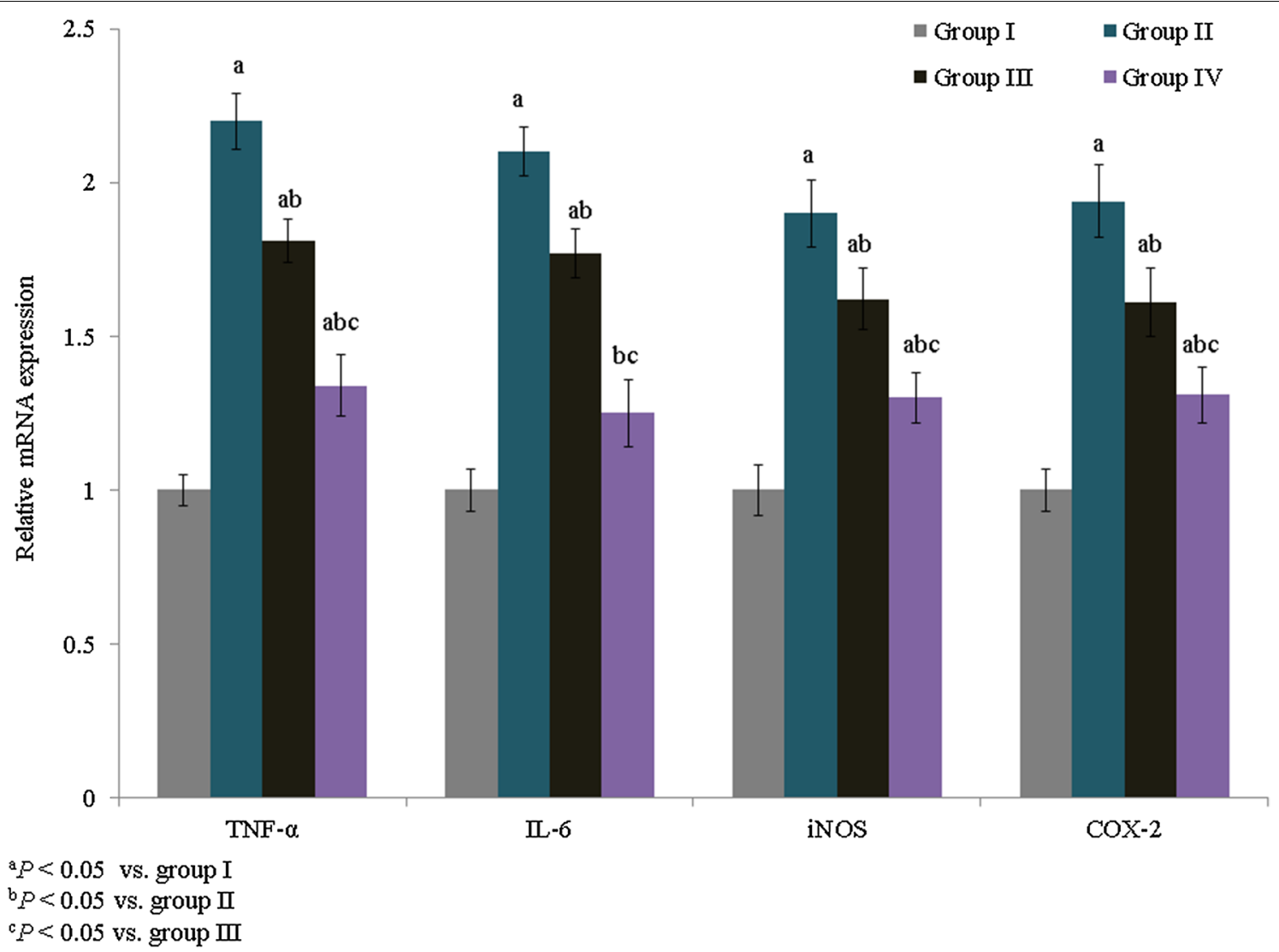

Fig. 3 Effect of E. hirta extract on the mRNA expression of TNF-a, IL-6, inducible nitric oxide synthase (iNOS), and cyclooxygenase 2 (COX-2) in neonatal asthmatic rats. Experimental data are given as the mean \pm SEM

proNGF, p53, and Bax were increased by 1.3-, 1.1-, 1.4-, and 0.9-fold, respectively, in group II, whereas Bcl-2 expression was reduced by 0.78 -fold. However, treatment with E. hirta extracts significantly reduced the mRNA expression levels of caspase-3, proNGF, p53, and Bax by more than 0.5-fold in group IV (Fig. $5, P<0.05$ ). Bcl-2 mRNA expression was increased by 1.4- and 3.1-fold in groups III and IV, respectively (Fig. 5, $P<0.05$ ).

Caspase-3 protein expression was determined immunohistochemically, and its expression increased dramatically (1.1-fold) in asthmatic rats. However, treatment with $E$. hirta extracts significantly reduced caspase-3 protein expression by $19 \%$ and $35.2 \%$ in groups III and IV, respectively (Fig. $6, P<0.05$ ). Airway and blood vessel narrowing and the accumulation of eosinophils in the lungs of neonatal asthmatic rats were noted. However, treatment with $E$. hirta extracts significantly reduced inflammation and eosinophil infiltration in the lungs (Fig. 7). The open field test was conducted to assess behavior and movement patterns. At higher concentrations, E. hirta extract significantly improved the behavior and movement patterns of asthmatic rats compared to their respective controls (Table $3, P<0.05$ ). The elevated plus maze test was performed to assess the anxiolytic activity of $E$. hirta extract. At a higher concentration, $E$. hirta extract exhibited significant anxiolytic activity in asthmatic rats compared to their respective controls (Table 3, $P<0.05$ ). At a higher concentration, E. hirta 


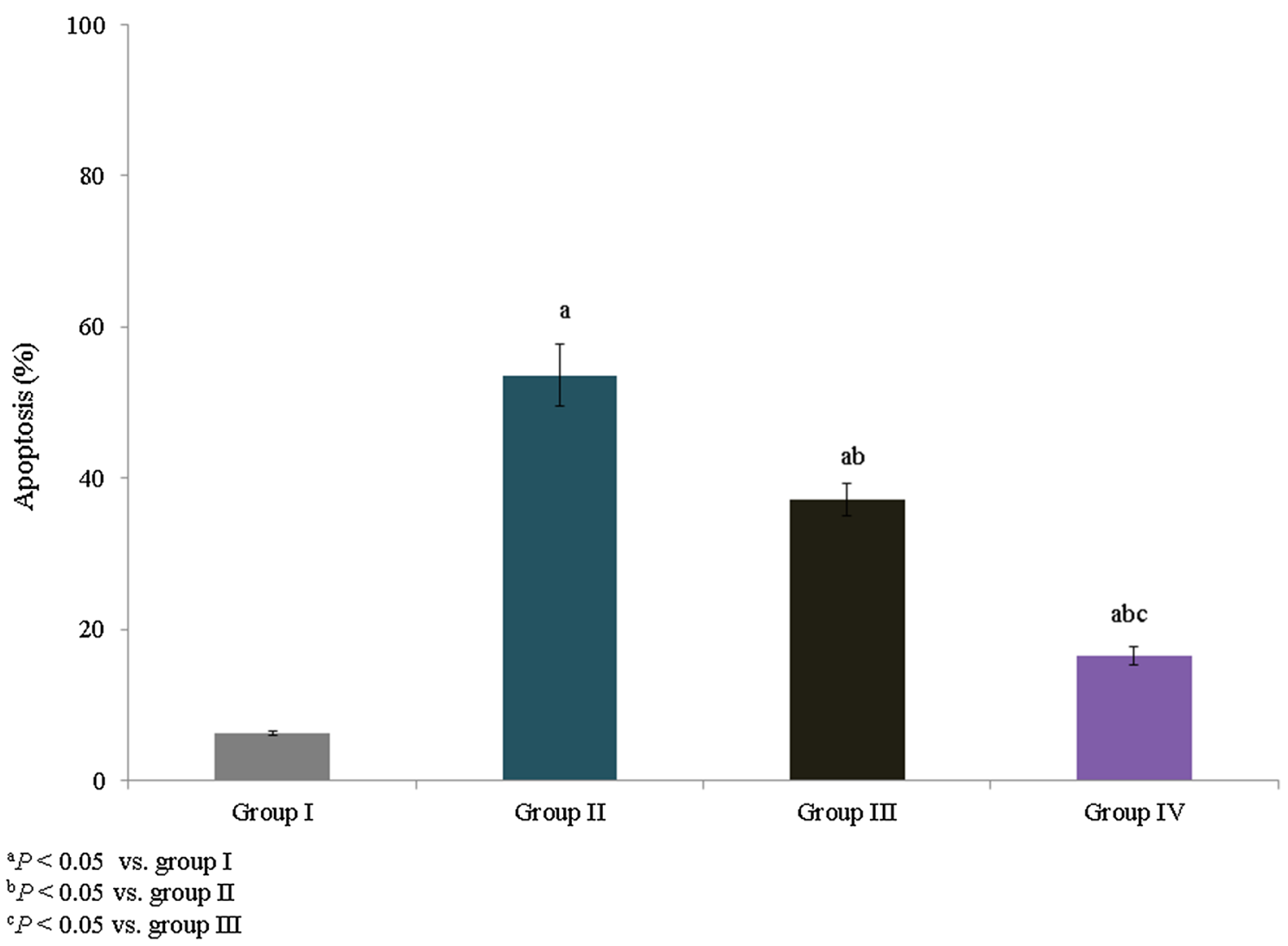

Fig. 4 Effect of E. hirta extract on apoptosis in neonatal asthmatic rats. Experimental data are given as the mean \pm SEM

extract was associated with significant increases in scores on the hole board and hole cross tests in asthmatic rats compared to their respective controls (Table $3, P<0.05$ ).

\section{Discussion}

We evaluated the anti-inflammatory and anxiolytic effects of $E$. hirta extract on neonatal asthmatic rats. Several researchers have reported that the extract of $E$. hirta exerts various pharmacological effects, including acting as an anxiolytic, sedative, anti-inflammatory, analgesic, and antipyretic agent. Indeed, it can be used to treat several conditions, such as hay asthma, worm infestations, bronchial disease, kidney stones, and bowel disease
(Sharma et al. 2007; Salles et al. 1999). Researchers have reported the anti-inflammatory activity of hydroxymethyl-2-furancarboxaldehyde (Brustugun et al. 2005; Xu et al. 2007). Graff and Pollack (2005) reported the protective effect of hydroxymethyl-2-furancarboxaldehyde against liver injury.

Kagoura et al. (1999) reported the various pharmacological activities of phytol, including its anti-inflammatory effects. Kagoura et al. (1999) also reported the anti-inflammatory and anti-bacterial effects of myristic acid. Wang et al. (2011) reported the antibacterial and antioxidant activities of 9,12,15-octadecatrien-1-ol against Staphylococcus aureus. The known activities of 


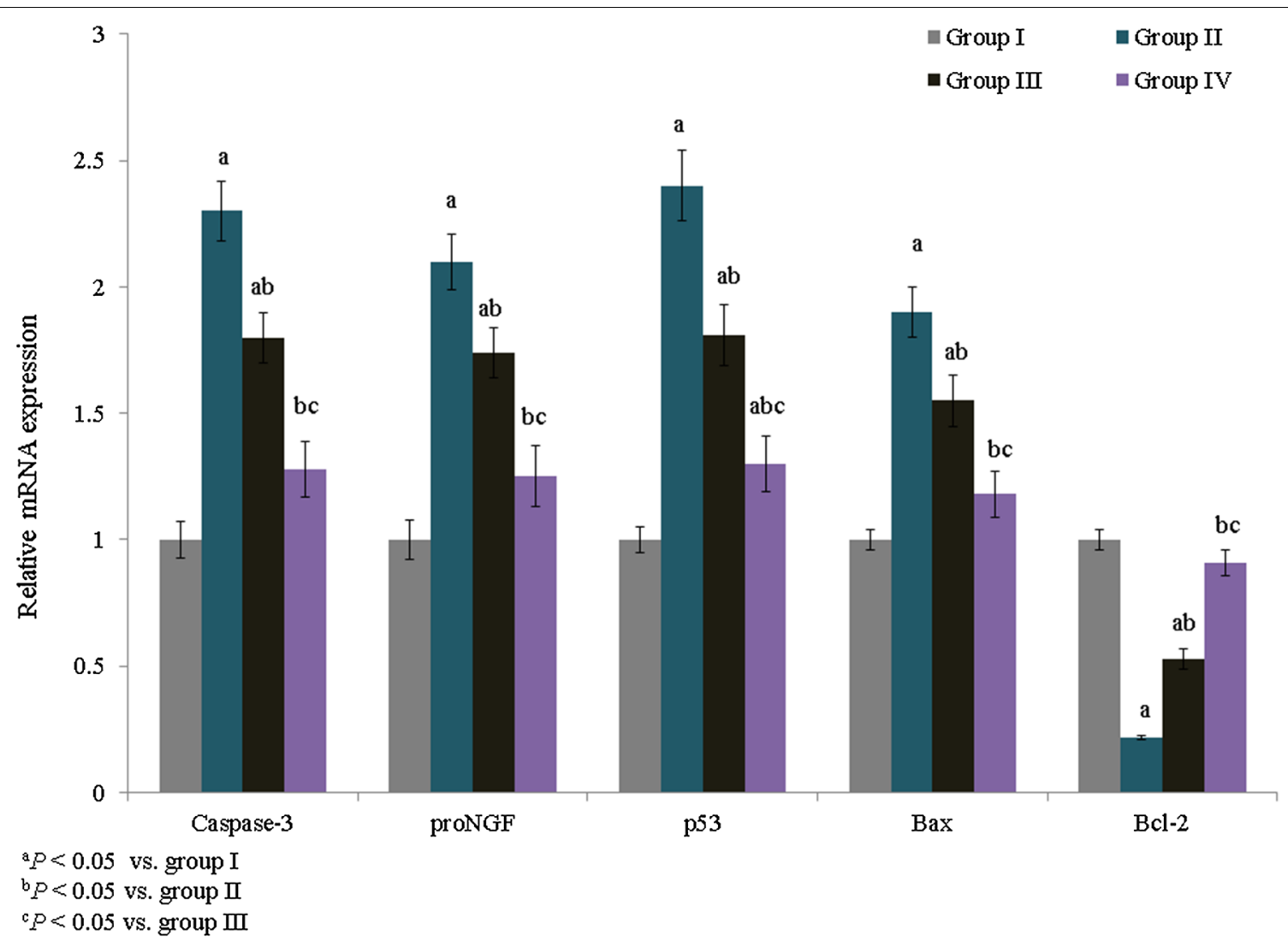

Fig. 5 Effect of E. hirta extract on the mRNA expression of caspase-3, proNGF, p53, Bax, and Bcl-2 in neonatal asthmatic rats. Experimental data are given as the mean \pm SEM

these compounds in E. hirta confirm our experimental findings. Heo et al. (2006) reported the critical role of phenolic compounds in free radical scavenging, and the antioxidant activity of these phenolic compounds is very crucial for decomposing peroxides and neutralizing free radicals (Kitada et al. 1979).

In this study, the bioactive compounds (phenolic compounds, 9,12,15-octadecatrien-1-ol, squalene and others) accounted for the anti-oxidant activity of E. hirta extract. Basma et al. (2011) reported the anti-oxidant activity of the methanolic extract of E. hirta. Several researchers have reported that the presence of fatty acids, phytol, and others in E. hirta extract accounts for its anti-inflammatory effects (Liu and Huang 2012; Kagoura et al. 1999). Shih et al. (2010) reported that the presence of flavones, glucosides, and tannins contributes to its anti-inflammatory activity through the inhibition of NO. Lefkowitz et al. (1999) reported increased NO generation through the increased production of cytokines, iNOS, and prostaglandins. Researchers have 

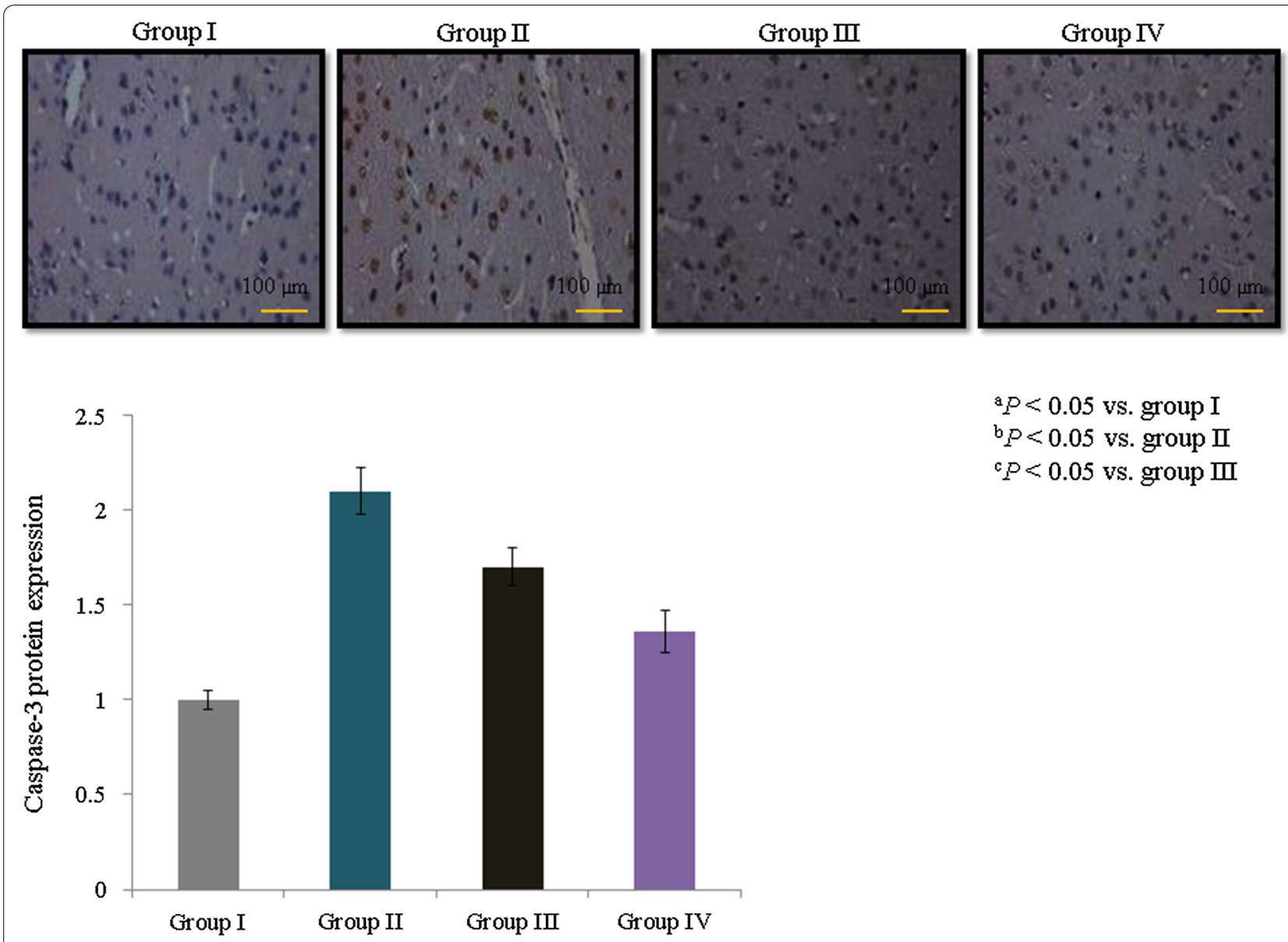

$a_{P}<0.05$ vs. group I

${ }^{b} P<0.05$ vs. group II $c_{P}<0.05$ vs. group III

Fig. 6 Effect of E. hirta extract on caspase-3 protein expression in neonatal asthmatic rats. Experimental data are given as the mean \pm SEM

indicated that increased NO production leads to oxidative stress, DNA damage and cell injury (Murphy 1999). Asthma is a well-known chronic airway inflammatory disorder that affects the lungs and causes coughing, wheezing, and chest tightness (Lee et al. 2010). The infiltration of eosinophils, lymphocytes, and mast cells into the airway wall results in mucus hypersecretion and causes allergic inflammation (Bochner and Busse 2004, 2005). Lung histopathological analysis confirmed severe inflammation in asthma-induced rats. However, treatment with $E$. hirta extract significantly attenuated inflammation, reflecting the protective effect of $E$. hirta 


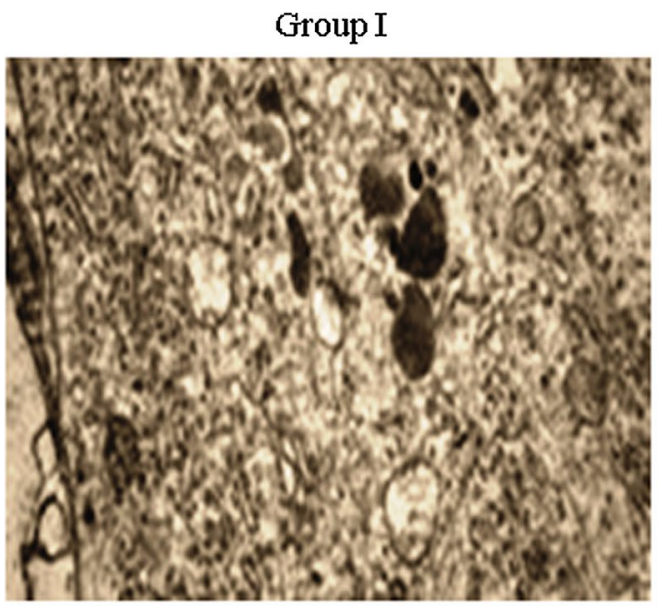

Group III

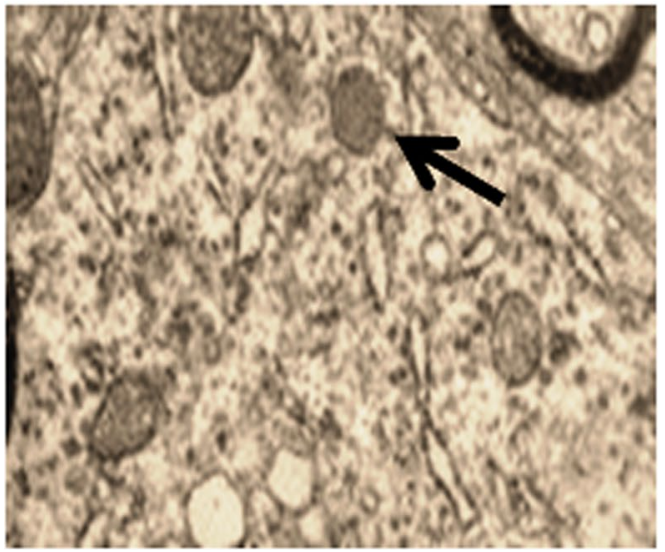

Group II

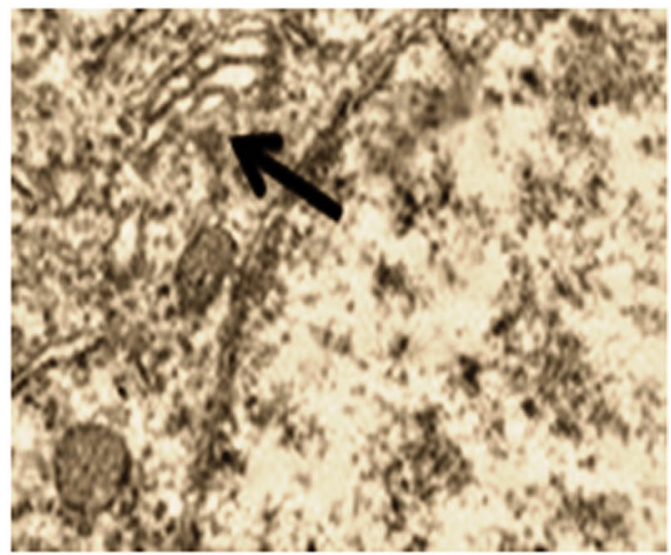

Group TV

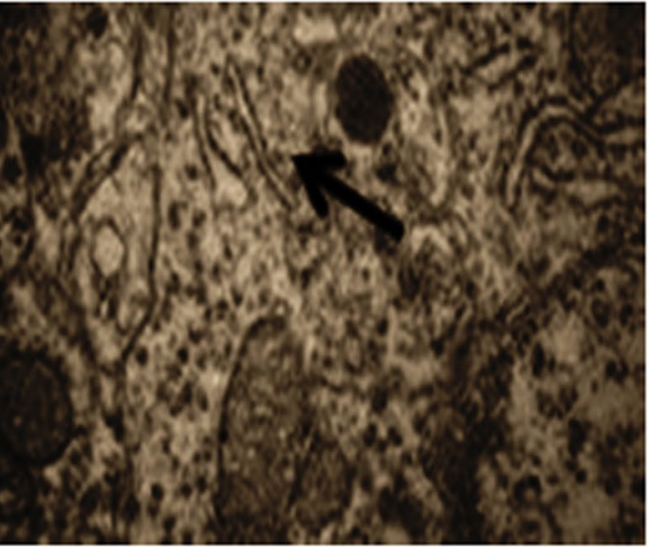

Fig. 7 Effect of E. hirta extract on the cellular architecture of lungs in neonatal asthmatic rats. Lung sections were stained and evaluated under a microscope. Magnification, $\times 40$ and $n=6$

Table 3 Effect of $E$. hirta extract on the ambulation in open field test, elevated plus maze, hole board and cross test

\begin{tabular}{lllll}
\hline Groups & Open field test & $\begin{array}{l}\text { Elevated } \\
\text { plus maze } \\
\text { test }\end{array}$ & $\begin{array}{l}\text { Hole board } \\
\text { test }\end{array}$ & $\begin{array}{l}\text { Hole } \\
\text { cross test }\end{array}$ \\
\hline Group I & 0 & 0 & 0 & 0 \\
Group II & $1.25 \pm 0.16^{\mathrm{a}}$ & $13.42 \pm 1.5^{\mathrm{a}}$ & $8.5 \pm 0.71^{\mathrm{a}}$ & $9.4 \pm 0.9^{\mathrm{a}}$ \\
Group III & $0.83 \pm 0.12^{\mathrm{a}}$ & $8.2 \pm 0.73^{\mathrm{ab}}$ & $6.2 \pm 0.4^{\mathrm{a}}$ & $6.6 \pm 0.7^{\mathrm{a}}$ \\
Group IV & $0.24 \pm 0.021^{\mathrm{abc}}$ & $3.1 \pm 0.03^{\mathrm{abc}}$ & $2.1 \pm 0.2^{\mathrm{abc}}$ & $2.2 \pm 0.2^{\mathrm{abc}}$
\end{tabular}

a $P<0.05$ vs. group I

b $P<0.05$ vs. group II

c $P<0.05$ vs. group III

against asthmatic inflammation. In summary, we conclude that $E$. hirta extract exerts anti-inflammatory and anxiolytic effects against asthmatic inflammation in neonatal rats.

\section{Abbreviations}

TNF-a: tumor necrosis factor-a; IL-6: interleukin; iNOS: inducible nitric oxide synthase; COX-2: cyclooxygenase-2; proNGF: nerve growth factor precursor; HPLC: high-performance liquid chromatography; BALF: bronchoalveolar lavage fluid; NO: nitric oxide; MDA: malondialdehyde; ROS: reactive oxygen species; GSH: reduced glutathione; SOD: superoxide dismutase; Gpx: glutathione peroxidase; AChE: acetyl-cholinesterase; TUNEL: terminal deoxynucleotidyl transferase dUTP nick end labeling.

\section{Authors' contributions}

$M X, L L, R Q$ and $M L$ conducted experiments and collected data. WH, GR and JZ carried out data interpretation, review of literature and manuscript drafting. All authors read and approved the final manuscript.

\section{Acknowledgements \\ None.}

\section{Competing interests}

The authors declare that they have no competing interests.

\section{Availability of data and materials}

Corresponding author could provide the all experimental data on valid request. 


\section{Consent for publication}

Not applicable.

\section{Ethics approval and consent to participate}

All the animal experiments were approved by ethics committee of The First Hospital of Qinhuangdao, No. 258 of Seaport Cultural Road, Qinhuangdao 066000, China.

\section{Funding}

None.

\section{Publisher's Note}

Springer Nature remains neutral with regard to jurisdictional claims in published maps and institutional affiliations.

Received: 20 August 2018 Accepted: 23 October 2018 Published online: 01 November 2018

\section{References}

Arutyunyan TV, Korystova AF, Kublik LN, Levitman MK, Shaposhnikova VV Korystov YN (2016) Taxifolin and fucoidin abolish the irradiation-induced increase in the production of reactive oxygen species in rat aorta. Bull Exp Biol Med 160:635-638

Basma AA, Zakaria Z, Latha LY, Sasidharan S (2011) Antioxidant activity and phytochemical screening of the methanol extracts of Euphorbia hirta L. Asian Pac J Trop Med 4:386-390

Bernal F, Hartung HP, Kieseier BC (2005) Tissue mRNA expression in the rat of newly described matrix metalloproteinase. Biol Res 38(2-3):267-271

Bochner BS, Busse WW (2004) Advances in mechanisms of allergy. J Allergy Clin Immunol 113:868-875

Bochner BS, Busse WW (2005) Allergy and asthma. J Allergy Clin Immuno 115:953-959

Brustugun J, Tonnesen HH, Edge R, Navaratnam S (2005) Formation and reactivity of free radicals in 5-hydroxymethyl-2-furaldehyde-the effect on isoprenaline photostability. J Photochem Photobiol B 79:109-119

Ding Y, Zou J, Li Z, Tian J, Abdelalim S, Du F, She R, Wang D, Tan C, Wang H, Chen W, Lv D, Chang L (2011) Study of histopathological and molecular changes of rat kidney under simulated weightlessness and resistance training protective effect. PLoS ONE 6(5):e20008

ErdenInal M, Akgün A, Kahraman A (2003) The effects of exogenous glutathione on reduced glutathione level, glutathione peroxidase, and glutathione reductase activities of rats with different ages and gender after whole-body Г-irradiation. J Am Aging Assoc 26:55-58

Fayzullina S, Martin LJ (2014) Detection and analysis of DNA damage in mouse skeletal muscle in situ using the TUNEL method. J Visualized Exp 94:52211

Feng D, Chengbin W, Jinyan D, Weiyi Z, Daijun X, Mianyang L (2014) Puerarin attenuates ovalbumin-induced lung inflammation and hemostatic unbalance in rat asthma model. Evid Based Complement Altern Med 2014:726740

Food and Agriculture Organization (2004) Trade in medicinal plants. Economic and Social Department, Food and Agriculture Organization of the United Nations, Rome

Graff CL, Pollack GM (2005) Nasal drug administration: potential for targeted central nervous system delivery. J Pharm Sci 94:1187-1195

Han RT, Kim S, Choi K, Jwa H, Lee J, Kim HY, Kim HJ, Kim HR, Back SK, Na HS (2017) Asthma-like airway inflammation and responses in a rat model of atopic dermatitis induced by neonatal capsaicin treatment. J Asthma Allergy 10:181-189

Heo SJ, Cha SH, Lee KW, Jeon YJ (2006) Antioxidant activities of red algae from Jeju Island. Algae 21:149-156

Huque A, Biswas S, Abdullah-Al-Mamun M, Bhuiyan JR, ur Rashid MH, Jahan A (2015) Analgesic, anti-inflammatory and anxiolytic activity evaluation of methanolic extract of Solanum surattense leaf in Swiss Albino mice model. Int J Pharm Clin Res 7(1):68-76

Jiang Y, Tu PF (2009) Analysis of chemical constituents in Cistanche species. J Chromatogr A 1216:1970-1979
Jordão AA Jr, Chiarello PG, Arantes MR, Meirelles MS, Vannucchi H (2004) Effect of an acute dose of ethanol on lipid peroxidation in rats: the action of vitamin E. Food Chem Toxicol 42(3):459-464

Kagoura M, Matsui C, Morohashi M (1999) Phytol is a novel tumor promoter on ICR mouse skin. Jpn J Cancer Res 90:377-384

Kelly C, Ward C, Stenton CS, Bird G, Hendrick DJ, Walters EH (1988) Number and activity of inflammatory cells in bronchoalveolar lavage fluid in asthma and their relation to airway responsiveness. Thorax 43(9):684-692

Kitada M, Igaradhi K, Hirose S, Kitagawa H (1979) Inhibition by polyamines of lipid peroxidase formation in rat liver microsomes. Biochem Biophys Res Commun 87:388-394

Kumar S, Malhotra R, Kumar D (2010) Euphorbia hirta: its chemistry, traditional and medicinal uses, and pharmacological activities. Pharmacogn Rev 4(7):58-61

Lee MY, Seo CS, Ha H, Jung D, Lee H, Lee NH, Lee JA, Kim JH, Lee YK, Son JK, Shin HK (2010) Protective effects of Ulmus davidiana var. japonica against OVA-induced murine asthma model via upregulation of heme oxygenase-1. J Ethnopharmacol 130:61-69

Lefkowitz DL, Gelderman MP, Fuhrmann SR, Graham S, Starnes JD, Lefkowitz SS, Bollen A, Moguilevsky N (1999) Neutrophilic lysozyme-macrophage interactions perpetuate chronic inflammation associated with experimental arthritis. Clin Immunol 91:145-155

Liu CH, Huang HY (2012) Antimicrobial activity of curcumin-loaded myristic acid microemulsions against Staphylococcus epidermidis. Chem Pharm Bull 60:1118-1124

Martinez FD (2007) Genes, environments, development, and asthma: a reappraisal. Eur Respir J 29(1):179-184

Murphy MP (1999) Nitric oxide, and cell death. Biochim Biophys Acta 1411:401-414

Nair R, Kalariya T, Chanda S (2005) Antibacterial activity of some selected Indian medicinal flora. Turk J Biol 29:41-47

Rates SMK (2001) Plants as a source of drugs. Toxicon 39(5):603-613

Rehg JE, Bush D, Ward JM (2012) The utility of immunohistochemistry for the identification of hematopoietic and lymphoid cells in normal tissues and the interpretation of proliferative and inflammatory lesions of mice and rats. Toxicol Pathol 40(2):345-374

Salles B, Sattler U, Bozzato C, Calsou P (1999) Repair of oxidative DNA damage in vitro: a tool for screening antioxidative compounds. Food Chem Toxicol 37:1009-1014

Shaheen TI, El-Naggar MI, Hussein JS, El-Bana M, Emara E, El-Khayat Z, Fouda MMG, Ebaid H, Hebeish A (2016) Antidiabetic assessment; in vivo study of gold and core-shell silver-gold nanoparticles on streptozotocin-induced diabetic rats. Biomed Pharmacother 83:865-875

Sharma JN, Al-Omran A, Parvathy SS (2007) Role of nitric oxide in inflammatory diseases. Inflammopharmacology 15:252-259

Sharma N, Samarakoon KW, Gyawali R, Park YH, Lee SJ, Oh SJ, Lee TH, Jeong DK (2014) Evaluation of the antioxidant, anti-inflammatory, and anticancer activities of Euphorbia hirta ethanolic extract. Molecules 19(9):14567-14581

Sheikh-Hamad D, Cacini W, Buckley AR, Isaac J, Truong LD, Tsao CC, Kishore BK (2004) Cellular and molecular studies on cisplatin-induced apoptotic cell death in rat kidney. Arch Toxicol 78(3):147-155

Shichinohe K, Shimizu M, Kurokawa K (1996) Effect of M-711 on experimental asthma in rats. J Vet Med Sci 58(1):55-59

Shih MF, Cheng YD, Shen CR, Cherng JY (2010) A molecular pharmacology study into the anti-inflammatory actions of Euphorbia hirta L. on the LPS-induced RAW 264.7 cells through selective iNOS protein inhibition. J Nat Med 64:330-335

Tavakkol Afshari J, Ghomian N, Shameli A, Shakeri MT, Fahmidehkar MA, Mahajer E, Khoshnavaz R, Emadzadeh M (2005) Determination of interleukin-6 and tumor necrosis factor-alpha concentrations in Iranian-Khorasanian patients with preeclampsia. BMC Pregnancy Childbirth 5:14

Wang L, Yang Z, Wang S, Wang S, Liu J (2011) Antioxidant and antibacterial activities of Camptotheca acuminate D. seed oil. Afr J Microbiol Res 5:5854-5862

Xu Q, Li YH, Lu XY (2007) Investigation on influencing factors of 5-HMF content in Schisandra. J Zhejiang Univ Sci B 8:439-445 